Case Report

\section{Blunt abdominal trauma with duodenal dissection: A case report}

\author{
Basile Essola ${ }^{1 *}$, Jean Baptiste Boumsong Batamag², \\ Jean Paul Engbang ${ }^{3}$, Dominique Djomo ${ }^{4}$, Esdras Ngaroua ${ }^{5}$, \\ Jacques Landenne ${ }^{6}$ and Jean Gustave Tsiagadigui ${ }^{7}$
}

1'Department of Surgery and Speciality, Douala University, Cameroon

${ }^{2}$ Department of Surgery, Regional Hospital, Edea, Cameroon

${ }^{3}$ Department of Surgery and Speciality, Douala University, Cameroon

${ }^{4}$ Department of Anesthesiology Gyneco Obstetrics and Pediatric Hospital, Douala, Cameroon

${ }^{5}$ Department of Surgery and Specialities, Douala University, Cameroon

${ }^{6}$ Department of Surgery, Centre Hospitalier de Wallonie Picarde Tournai, Belgium

${ }^{7}$ Department of Surgery and Specialities, Douala University, Cameroon

\section{Abstract}

We describe a new case of duodenal wound with complete transection in a 22-year-old patient following a motorcycle accident. He presented to the emergency room of the rural Regional Hospital of Edéa in Cameroon with a clinical picture of acute abdomen and post-trauma hemodynamic instability. A peritoneal puncture brought back an incoagulable blood. An exploratory laparotomy revealed a large hemoperitoneum mixed with food debris. A tear of the omentum and transverse mesocolon and a complete section of the third duodenum at the beginning of its free portion were observed. The surgeon performed emergency closure of both duodenal stumps and performed an isoperistaltic lateral gastrojejunal bypass. A transfer to a specialized center for a more anatomical continuity was considered, but the imminence of a humanitarian mission in the hospital prompted the surgeon to seize the opportunity of this mission for the reoperation. This surgical revision was performed on the fifth postoperative day. A resection of the distal duodenal stump and the adjacent jejunal segment including the anastomosis was performed. Continuity was restored by a mechanical duodenal-jejunal anastomosis. The patient was discharged on the $18^{\text {th }}$ postoperative day. This type of lesion is difficult to manage in an emergency situation in a structure with limited technical resources. Unfortunately, surgeons treating polytraumatized civilians are encountering an increasing number of blunt duodenal wounds requiring laborious management.

\section{More Information}

*Address for Correspondence: Essola Basile, Department of Surgery and Speciality, Douala University, Cameroon, Email: essolab@yahoo.fr

Submitted: May 11, 2021

Approved: July 27, 2021

Published: July 28, 2021

How to cite this article: Essola B, Batamag JBB, Engbang JP, Djomo D, Ngaroua E, et al. Blunt abdominal trauma with duodenal dissection: $\mathrm{A}$ case report. Arch Case Rep. 2021; 5: 023-026.

DOI: 10.29328/journal.acr.1001051

Copyright: ๑ 2021 Essola B, et al. This is an open access article distributed under the Creative Commons Attribution License, which permits unrestricted use, distribution, and reproduction in any medium, provided the original work is properly cited.

Keywords: Duodenal wound-blunt trauma; Duodeno-jejunal anastomosis; Edéa Regional Hospital

Check for updates

OPEN ACCESS

\section{Introduction}

Duodenal injuries, due to their retroperitoneal location, are a diagnostic and treatment challenge to the surgeon; especially in rural hospital in low incomes countries. They are often identified in a late stage, and thus associated with increased morbidity and mortality. The purpose of this paper is to present by a new case report how a complete third duodenal transection was managed in a rural hospital at Edea in Cameroon.

\section{Case presentation}

A 22-year-old patient presented to the emergency room of the Edéa Regional Hospital in the earlier in the morning with diffuse abdominal pain and vomiting after a motorcycle accident in a context of drunkenness. The accident occurred at 3:00 a.m. after hitting a speed bump. The patient fell and landed on his left hemisphere and arrived two hours later at the emergency room accompanied by the police. He had no medical or surgical history. The physical examination revealed an hypotensive patient at $8 / 6 \mathrm{~mm} \mathrm{Hg}$ and a heart rate of 100 beats per minute, respiratory rate at $25 /$ minute, Glasgow score at $14 / 15$. He presented with a $2-\mathrm{cm}$ wide and $1 \mathrm{~cm}$ deep wound on the mucous side of the lower lip and a superficial linear wound on the anterior part of the tongue, an alveolar-dental trauma with total avulsion of teeth 11,21 and 22. At the thoracic level, dermabrasions of the left hemi thorax were noted, the cardiopulmonary auscultation was normal. At the abdominal side, there were dermabrasions of the left hypochondrium, moderate bloating, generalized defensiveness and abolition of peristalsis. A biological examination (Table 1) showed white blood cells at 10500 / 
Table 1: main results of paraclinic exams.

\begin{tabular}{|c|c|c|}
\hline Exams & Value & Normal value \\
\hline White blood cells & $10.500 / \mathrm{mm}^{3}$ & $4000-10.000 / \mathrm{mm}^{3}$ \\
\hline Hemoglobin & $12 \mathrm{~g} / \mathrm{L}$ & $12-17 \mathrm{~g} / \mathrm{L}$ \\
\hline International Normalized Ratio (INR) & 1,89 & $0,85-1,15$ \\
\hline
\end{tabular}

$\mathrm{mm}^{3}$ Hemoglobin at $12 \mathrm{~g} / \mathrm{L}$ and International Normalized Ratio +(INR) at 1.89 .

The ultrasound being unavailable, a peritoneal lavage puncture will objectified a hemoperitoneum. The patient was considered as unstable polytraumatized with abdominal contusion, hemoperitoneum, facial trauma with avulsion of three teeth. An urgent exploratory laparotomy was indicated.

Preoperative resuscitation with geloplasma infusion, antibiotics and analgesics followed by median laparotomy under general anesthesia. Exploration of the abdominal cavity showed extensive hemoperitoneum, food debris, and bile. A large median tear of the greater omentum and the transverse mesocolon was noted. After peritoneal cleansing, a complete section of the third portion of the duodenum at the emergence of its mobile part is objective (Figure 1). Restoration of continuity by direct suture proves to be topographically laborious and cannot be envisaged in an emergency situation with limited technical resources. The duodenal stumps were closed with Vicryl 2.0 in separate stitches, followed by a lateral iso peristaltic gastrojejunal anastomosis with polydiaxonone. A peritoneal cleansing and a drainage in front of the anastomosis were carried out and an antibiotic therapy with Ceftriaxone $1 \mathrm{~g}$ and Metronidazole $500 \mathrm{mg} / 8 \mathrm{~h}$ was prescribed A transfer to a specialized center for a more physiological anastomosis was considered but the patient did not have sufficient financial means, so the surgeon preferred to wait for an imminent humanitarian mission in the hospital of Edéa in order to carry out this intervention on the spot. In the meantime, the patient remained on antibiotics and was taken back into surgery during the humanitarian mission on the fifth postoperative day. He had a large biloma diagnosed intraoperatively on loosening leakage of the proximal duodenal suture. After peritoneal lavage, a resection of the distal duodenal stump and the adjacent jejunal segment including the anastomosis was performed. Proximally, a mechanical termino-lateral duodenal-jejunal anastomosis with a $29 \mathrm{~mm}$ ILS circular stapler was performed and the patient was placed on parenteral nutrition with Astymin 1 vial / day for 11 days. The postoperative course was complicated by a wall infection

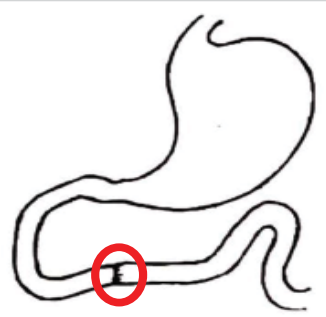

Figure 1: Showing the site of duodenal injury by the blunt. from the $6^{\text {th }}$ day after the operation, treated by local care with Betadine. We noted a resumption of transit on the $7^{\text {th }}$ day post-reoperation. A small bowel transit examination with gastrografine performed on the $10^{\text {th }}$ postoperative day did not show any stenosis or anastomotic fistula. The patient was discharged on the 18th postoperative day with an ambulatory follow-up.

\section{Discussion}

The first successful repair of a duodenal rupture was reported in 1896 [1] and remained the only case described until 1905 [2]. Since then the number of patients with duodenal wounds has increased with the number of motor vehicle and criminal accidents [2-4].

Duodenal wounds in blunt trauma can be simple, or complex with extension to adjacent organs. The second portion of the duodenum is relatively rigidly fixed with its peritoneal attachments and interlocking with the pancreas. The third portion is more vulnerable because it can be compressed against the lumbar spine [5]. A blowout theory is sometimes considered when the pylorus is closed and the Treitz angle is acute, an air trap is formed that can result in rupture if hyper pressure is applied [5]. Causal forces are numerous; crushing and explosion, blows in traffic accidents, rapid deceleration causing steering wheel impact to the epigastrium [5]. The force may be minimal and the causal accident ignored because it was insignificant [6]. Associated injuries may be seen in organs such as the liver, pancreas, stomach, omentum, intestines, and gallbladder. Intraperitoneal lesions may distract the surgeon's attention and pancreatic-duodenal lesions may remain unrecognized [5]. A duodenal injury can present a formidable challenge to the surgeon and an inability to manage it can have devastating results [7].

\section{Clinical}

The history is paramount in a situation of abdominal trauma, provided the patient is conscious, and possibly using a hetero-anamnesis to describe the circumstances of the accident. Even in the modern era where technology plays an essential role in diagnosis, the surgeon's clinical judgment based on the history and physical examination is still crucial in the evaluation of a patient with blunt trauma [4]. A duodenal injury following a blunt force can occur either by crushing of the duodenum near the lumbar spine which is a rigid structure, or shear forces which can occur during falls or in barotrauma as seen in seat belt injuries [7]. Our patient had a motorcycle fall after hitting a speed bump which can generate complex body movements combining the effect of blowing, deceleration shear and compression. Although on clinical examination only superficial skin abrasions are observed, the possibility of deep lesions should be kept in mind. Inevitably, deep lesions are associated with tachycardia and hypotension in favor of hemorrhagic or septic shock. In the majority of retroperitoneal perforations, there is initially only mild upper abdominal 
tenderness with a progressive increase in temperature, tachycardia and occasionally vomiting [7]. After a few hours the duodenal contents spill into the peritoneal cavity with development of peritonitis. This peritonitis, initially localized in the retroperitoneal area, will pass through Winslow's hiatus or another breach of the mesocolon and spread to the entire abdomen, resulting in a frank acute abdomen. Examination of the abdomen will reveal signs of peritoneal irritation that may be discrete or absent in the early stages. Testicular pain has sometimes been described by irritation of the right testicular nerve [5]. The possibility of a spinal fracture should also be kept in mind, depending on the complaints and the kinetics of the accident. Our patient was hypotensive, tachycardic with wooden bellies and abolition of peristalsis. He also had a nonlife-threatening oral-facial trauma. On this clinical basis the patient was considered as polytraumatized with an abdominal drama. A peritoneal lavage can quickly help in the diagnosis of an unstable patient, a limited technical platform and/or the unavailability of imaging personnel. This was the case at Edéa Hospital where the patient arrived at 3:00 a.m., with a technical platform limited to conventional radiology and ultrasound, and where the staff was not available. A peritoneal puncture was sufficient to objectify the hemoperitoneum and establish the surgical indication.

\section{At the para-clinical level}

The biological work-up is not very helpful in acute cases. However, it may show leukocytosis, anemia and increased amylase. The amylase level is more interesting if a profile is made and not an isolated determination [8]. Biology will be more contributory for preoperative examinations and will serve as a comparative basis for follow-up. In a context of limited financial means, this biological examination is reduced to the strict minimum. Our patient had a blood count and formula, coagulation tests, ionogram and renal function tests which showed no abnormalities.

Imaging the plain $\mathrm{x}$-ray of the abdomen may show air in the right psoas muscle, around the right kidney and in front of the lumbar spine, and aerobilia may be seen [6,7]. A lumbar transverse process fracture may be indicative of the force of the trauma and predictive of a duodenal injury [7].

A gastrographine transit or a barium enema can detect perforations and hematoma [7]. This examination can also be used postoperatively to exclude a fistula, a stenosis and to authorize enteral feeding.

Ultrasound: diagnostic means used in the absence of CT scan [5] because it can be easily moved to the patient's foot, especially if unstable. This examination can evaluate the extent of a peritoneal effusion, lesions of the solid viscera but is not very suitable for the hollow viscera. This examination is more easily accessible in Cameroon but for our patient, the staff was not available to perform the examination.

CT scan is the most sensitive examination for a precise and topographic lesion assessment. With the injection of contrast, it allows the objectification of active bleeding $[9,10]$. A digestive preparation with gastrographine makes the examination even more efficient to detect perforations. However, the patient must be sufficiently stable to perform such explorations. CT scan is not available at Edéa Hospital.

Our patient did not benefit from any iconography preoperatively for reasons of limited technical platform at Edéawich is rural Hospital and availability of personnel. However, a gastrographine transit was performed on the $10^{\text {th }}$ postoperative day, allowing enteral feeding (Figure 1). The quality of picture was not good but no sign of anastomotic leakage.

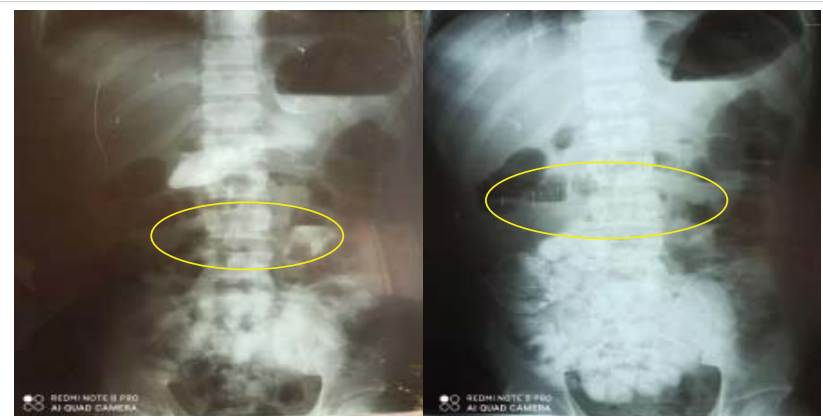

No sign of anastomosis leakage at the area of suture.

\section{Treatment}

Abdominal CT scan and small bowel transit may allow the diagnosis of blunt trauma but exploratory laparotomy is the examination of choice in case of strong suspicion of duodenal injury in the face of absent or equivocal radiological signs [7]. This option will be privileged in an emergency context and limited technical platform in particular in cases of duodenal injuries where early intervention is part of a significant difference in patient outcome and prognosis. The treatment is done according to the classification of the lesions (Table 2).

Advance one grade for multiple injuries to the same organ. Based on most accurate assessment at autopsy, laparotomy, or radiologic study.

Our patient has a grade III lesion (Figure 1).

3 treatments options can be considered:

1-A terminal duodenal suture provided that both stumps are accessible and mobilizable [6,7] (Figure 2a).

2-A closure of the 2 stumps associated with a gastroenteroanastomosis [6,7] (Figure 2b).

3-A duodeno-jejunal terminal-lateral or latero-terminal anastomosis (Figure 2c,d).

Our patient benefited from the emergency assembly (Figure 2b). As the proximal stump was barely accessible, the termino-terminal suture proved to be difficult and risky in the 
Table 2: American Association for the Surgery of Trauma - Organ Injury Scale (AAST-OIS) for duodenum [11]

\begin{tabular}{|c|c|c|c|}
\hline Gradelnjury description & AlS & \\
\hline I & Hematoma & Involving single portion of the duodenum & 2 \\
\hline & Laceration & Partial thickness, no perforation & 3 \\
\hline II & Hematoma & Involving more than one portion & 2 \\
\hline & Laceration & Disruption < 50\% of circumference & 4 \\
\hline III & Laceration & Disruption 50\%-75\% circumference of D2 & 4 \\
\hline & & Disruption 50\%-100\% circumference of D1, D3, D4 & 4 \\
\hline IV & Laceration & Disruption > 75\% circumference of D2 & 5 \\
\hline & & Involving ampulla or distal common bile duct & 5 \\
\hline V & Laceration & Massive disruption of duodenopancreatic complex & 5 \\
\hline & & Vascular Devascularization of duodenum & 5 \\
\hline
\end{tabular}

D1 $=1^{\text {st }}$ portion duodenum, D2 $=2^{\text {nd }}$ portion duodenum, D3 $=3^{\text {rd }}$ portion duodenum, D4 $=4^{\text {th }}$ portion duodenum.

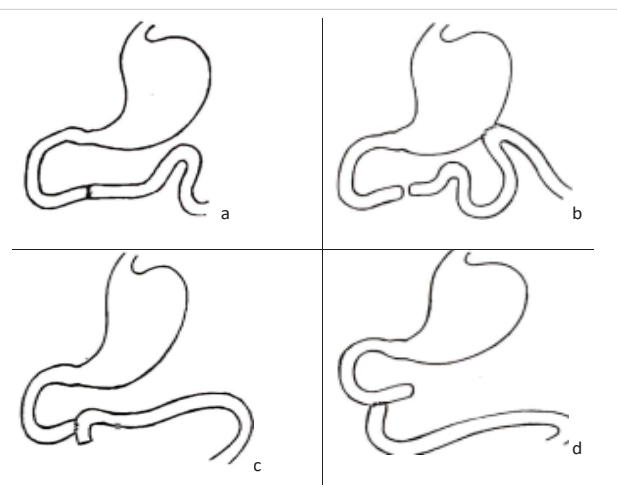

Figure 2: Shows four ways to repair third duodenal transection injury, a) Terninoterminal suture of third duodenum, b) Gastro-enterostomy with closure of duodenal stumps, c) Termino-lateral duodeno-jejunostomy, d) Latero-terminal duodenojejunostomy.

context of an emergency in the field of peritonitis at a late hour, without any device to perform a mechanical suture. However, the Figure $2 \mathrm{~b}$ set-up may not only have the disadvantage of forcing the bilio-pancreatic secretions to flow back into the stomach with consequences at the physiological level, but also a duodenal high pressure which may generate a fistula at the level of the duodenal stump and lead to a biloma which may evolve into biliary peritonitis. Our patient did indeed present a biloma following the release of the proximal duodenal stump, and we therefore definitively treated the patient with a duodenal-jejunal suture after having removed the emergency gastric bypass (Figure 2c).

\section{Prognosis}

The amount of fluid passing through the duodenum is greater than 6 liters per day. A fistula in this area can cause severe hydrolytic imbalance on the one hand and chemical peritonitis on the other [7]. The morbidity when the operation is delayed for 24 hours is $62 \%$ [12]. From 1910 to 1952 , the mortality rate for duodenal wounds varied from 90 to $20 \%$ [5]. Currently this mortality rate varies between $11 \%$ and $40 \%$ if the patient is not treated within 24 hours [13].

\section{Conclusion}

Even in the modern era where technology plays an essential role in diagnosis, the surgeon's clinical judgment based on the history and physical examination is still a crucial point in the evaluation of a patient with blunt trauma. Gastrojejunal bypass with closure of the duodenal stumps in case of complete section of the third duodenum in an emergency situation where a duodeno - duodenal suture cannot be performed safely is considered as a therapeutic option. A surgical revision can be performed in a second phase for a more physiological restoration of continuity.

\section{References}

1. Hildebrands Jahresber. Meerwein. Herczel. 1896; 691.

2. Corley RD, Norcross WJ, Shoemaker WC. Traumatic Injuries to the Duodenum: A Report of 98 Patients. Ann Ann Surg. 1975; 181: 92-98. PubMed: https://pubmed.ncbi.nlm.nih.gov/1119875/

3. Burrus GR, Howell JF, Jordan GL Jr. Traumatic Duodenal Injuries. An Analysis of 86 Cases. J Trauma. 1961; 1: 96-104. PubMed: https://pubmed.ncbi.nlm.nih.gov/13689228/

4. Cleveland HC, Waddell WR. Retroperitoneal Rupture of the Duodenum Due to Nonpenetrating Trauma. Surg Clin North Am. 1963; 43: 413. PubMed: https://pubmed.ncbi.nlm.nih.gov/14021722/

5. Hanley JA. Retroperitoneal duodenal rupture. BrMed J. 1958; 1:505-506. PubMed: https://pubmed.ncbi.nlm.nih.gov/13510710/

6. Ivatury RR, Nassoura ZE, Simon RJ, Rodriguez A. Complex duodenal injuries. Surg Clin North Am. 1996; 76: 797-812.

PubMed: https://pubmed.ncbi.nlm.nih.gov/8782474/

7. DegiannisE,BoffardK.Duodenalinjuries. BriJSurg. 2000;87:1473-1479. PubMed: https://pubmed.ncbi.nlm.nih.gov/11091233/

8. Levison MA, et al. Duodenal trauma: Experience of the trauma center. J Trauma. 1996; 40: 1037-1046.

9. Kunin JR, Korobkin M, Ellis JH, Francis IR, Kane NM, et al. Duodenal injuries caused by blunt abdominal trauma: Value of CT in differentiating perforation from hematoma. AJR Am J Roentgenol. 1993; 160: 1221-1223. PubMed: https://pubmed.ncbi.nlm.nih.gov/8498221/

10. Timaran $\mathrm{CH}$, Daley BJ, Enderson BL. Role of duodenography in the diagnosis of blunt duodenal injuries. J Trauma. 2001; 51: 648-651. PubMed: https://pubmed.ncbi.nlm.nih.gov/11586153/

11. Moore EE, Cogbill TH, Malangoni A, Jurkovich GS, Champion HR, et al. Organ Injury Scaling II: Pancreas, Duodenum, Small Bowel, Colon, and Rectum. J Trauma. 1990; 30: 1427- 1429.

PubMed: https://pubmed.ncbi.nlm.nih.gov/2231822/

12. Lin BC, Chen RJ, Fang JF, Hsu YP, Kao YC, et al. Management of blunt major pancreatic injury. J Trauma. 2004; 56: 774-778.

PubMed: https://pubmed.ncbi.nlm.nih.gov/15187740/

13. Bankar SS, Gosavi VS, Hamid M. Duodenal transection without pancreatic injury following blunt abdominal trauma. J Surg Tech Case Rep. 2014; 6: 67-69.

PubMed: https://pubmed.ncbi.nlm.nih.gov/25598947/ 